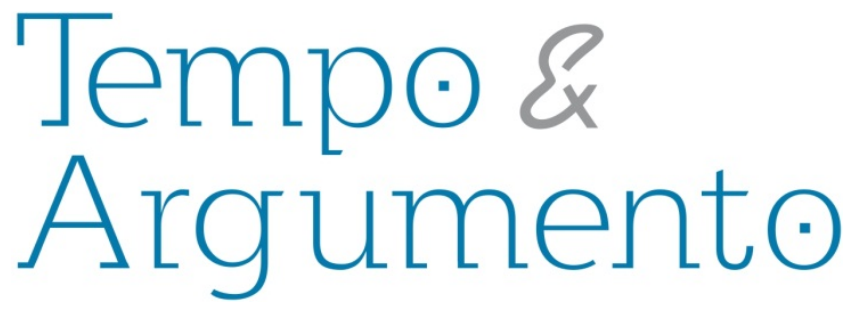

\title{
Resistência e gênero nos arquivos das ditaduras militares do Cone Sul
}

\section{Resumo}

Este artigo apresenta uma reflexão sobre os arquivos que guardam acervos sobre as ditaduras nos países do Cone Sul (Argentina, Bolívia, Brasil, Chile, Paraguai e Uruguai) que tem sido explorados no Projeto Gênero, Feminismos e Ditaduras pelo Laboratório de Estudos de Gênero e História da Universidade Federal de Santa Catarina. Busca mostrar como se pode encontrar perspectivas de gênero em acervos que originalmente tiveram como principal propósito a repressão aos movimentos políticos de resistência às ditaduras, ou que se constituíram justamente no esforço de memória desta resistência, mas que não problematizaram especialmente as questões de gênero. A reflexão pretende mostrar que o gênero é um aspecto importante na constituição dos discursos da resistência nestes países.

Palavras-chave: Gênero. Ditadura. Cone Sul. Arquivos. Memória.

\author{
Cristina Scheibe Wolff \\ Doutora em História Social. \\ Professora da Universidade \\ Federal de Santa Catarina. \\ cristiwolff@gmail.com
}

\footnotetext{
Para citar este artigo:

WOLFF, Cristina Scheibe. Resistência e gênero nos arquivos das ditaduras militares do Cone.

Revista Tempo e Argumento. Florianópolis, v. 5, n.9, jan./jun. 2013. p. 451 - 471.
}

DOI: $10.5965 / 2175180305092013451$

http://dx.doi.org/10.5965/2175180305092013451 


\title{
Resistence and gender in the archives of the Cone Sul military dictatorships
}

\begin{abstract}
This article presents a reflection on the archives that hold collections on dictatorships in the countries of the so called Cone Sul (Argentina, Bolivia, Brazil, Chile, Paraguay and Uruguay) which have been explored in the Project Gender, Feminisms and Dictatorships by the Laboratory for the Study of Gender and History of the Federal University of Santa Catarina. It aims to show how one can find gender perspectives in collections that originally had as their main purpose the repression against political movements of resistance to dictatorships, or that were constituted precisely in the memory effort of this resistance, but that did not problematized particularly gender issues. The reflection is intended to show that gender is an important aspect in the constitution of resistance discourses in these countries
\end{abstract}

Keywords: Gender. Dictatorship. Cone Sul. Archives. Memory. 
As reflexões que vou apresentar hoje são resultado de um projeto coletivo de pesquisa que na verdade é a combinação de duas pesquisas principais: Movimento de Mulheres e Feminismos em tempos de ditadura militar no Sul Cone Sul (1964-1989), coordenado por Joana Maria Pedro ${ }^{1}$ e $O$ gênero da resistência na luta contra as ditaduras militares no Cone Sul 1964-1989 coordenado por Cristina Scheibe Wolff. ${ }^{2}$ A partir destes projetos, vários estudantes de graduação, mestrado, doutorado e pós-doutorado propuseram projetos menores englobados por ele. Em maio de 2009 organizamos o Colóquio Internacional Gênero, Feminismos e Ditaduras no Cone Sul, com a participação de conferencistas dos diversos países do Cone Sul, e foram apresentados cerca de 300 trabalhos sobre o tema. ${ }^{3}$ Além disso, recentemente foi lançado o livro Resistências, gênero e feminismos contra as ditaduras no Cone Sul, que reúne trabalhos realizados pela equipe do projeto. ${ }^{4}$ Como os projetos têm propostas de pesquisa, objetivos e metodologia que se intercruzam, bem como uma base geográfica e temporal que coincide, a equipe de pesquisa tem trabalhado em conjunto nas seguintes atividades: coleta de material em arquivos, através da digitalização de documentos; realização, transcrição e revisão de entrevistas orais; levantamento bibliográfico com a formação de um acervo no Laboratório de Estudos de Gênero e História (LEGH); discussão de textos, livros e metodologias; organização e participação em eventos e publicações. Dessa forma percorremos em conjunto muitos arquivos e outros espaços de memória nos diversos países. Tentarei apresentar um pequeno panorama destes espaços e refletir sobre os problemas que eles nos apresentam, e suas potencialidades, a partir de uma perspectiva centrada no gênero.

\footnotetext{
${ }^{1}$ Este projeto foi financiado pelo CNPQ, com bolsa de produtividade $1 C$, além de auxílios pesquisa e de obter recursos da FAPESC.

${ }^{2}$ Projeto financiado pelo CNPq com bolsa de produtividade $1 \mathrm{D}$, auxílio pesquisa e bolsas de iniciação científica.

${ }^{3}$ Este colóquio gerou anais eletrônicos, disponíveis no site: http://www.coloquioconesul.ufsc.br/ e o livro PEDRO, Joana Maria e WOLFF, Cristina Scheibe. Gênero, Feminismos e Ditaduras no Cone Sul. Florianópolis: Editora Mulheres, 2010. Disponível em formato pdf no site: http://www.ieg.ufsc.br/livros_eletronicos.php

${ }^{4}$ PEDRO, Joana Maria; WOLFF, Cristina Scheibe e VEIGA, Ana Maria.(org.) Resistências, gênero e feminimos contra as ditaduras no Cone Sul. Florianópolis: Mulheres, 2011.
} 
Nas décadas de 1960 e 1970, mais ou menos simultaneamente, a Argentina, a Bolívia, o Brasil, o Chile, o Paraguai e o Uruguai viveram regimes ditatoriais de cunho civilmilitar, inspirados na Doutrina da Segurança Nacional. A maior justificativa utilizada para legitimar esses regimes de exceção foi a luta contra o comunismo, que nestes tempos de Guerra Fria, atemorizava as elites e classes médias desses países. Dessa forma os golpes militares contaram muitas vezes com o apoio de amplos setores da sociedade. Além disso, com a exceção do Chile que tiveram decênios de regimes democráticos, as ditaduras não eram novidades para os países do Cone Sul.

Ao passo que as ditaduras foram implantadas, também começaram a surgir organizações de direitos humanos e de resistência contra as ditaduras e defesa da cidadania. Grupos da Igreja Católica, bem como de outras igrejas, ligados à chamada Teologia da Libertação, abrigaram grupos de pessoas com posições de esquerda e promoveram organizações comunitárias e iniciativas pastorais, que foram naquele momento muito importantes para o desenvolvimento de ações a favor dos direitos humanos.

Também foi nesse período que se desenvolveu na América do Sul e no mundo inteiro a «Nova Esquerda», inspirada principalmente na Revolução Cubana e na Revolução Chinesa, que questionava as oreintações dos partidos comunistas alinhados com a posição da União das Repúblicas Socialistas Soviéticas. Os grupos da Nova Esquerda se organizaram com a esperança de que pequenos grupos de vanguarda poderiam se estender a outras camadas sociais e promover revoluções. Em outros casos constituíram desde seu nascimento respostas diretas às ditaduras, acreditando que para fazer frente à repressão e à violência dos estados militarizados era preciso organizar uma luta de resistência armada.

O mundo ocidental esse período também foi marcado pela segunda onda do Movimento Feminista e pela contracultura. Apesar das ditaduras, a contracultura e o feminismo foram important a formação das subjetividades da geração de jovens destes diferentes países. Em 1968, enquanto na França os estudantes protestavam contra as normas acadêmicas rígidas e lutavam ao lado do movimento sindical, e os estadounidenses se posicionavam contra a Guerra do Vietnã, grandes manifestações 
A doutrina da Segurança Nacional foi elaborada a partir da política estabelecida pelo presidente norte-americano Harry Truman, a partir de 1947. Esta doutrina colocava o comunismo e os movimentos sociais de esquerda como ameaças à segurança interna dos Estados Unidos, e, a partir da Revolução Cubana, passou a incluir todos os países da América Latina. Para isso os Estados Unidos passaram a financiar equipamentos e treinamento de forças policiais e forças armadas de diversos países da América, com vistas a divulgar a doutrina e a evitar que acontecesse em outros países o mesmo que aconteceu em Cuba. ${ }^{5}$

Uma das principais estratégias usadas para combater o "comunismo" foi o que foi chamado de guerra de "inteligência”, a guerra contrarrevolucionária. Esta estratégia, também chamada de guerra antisubversiva, foi desenvolvida especialmente a partir das experiências francesas nas Guerras da Indochina, Vietnã e Argélia. ${ }^{6}$ E foi divulgada através de "cursos" e consultorias de oficiais franceses, no Brasil, na Argentina e especialmente através da Escola das Américas, no Panamá, patrocinada pelos Estados Unidos, por onde passaram dezenas de milhares de oficiais latino-americanos. Esta estratégia procurava recolher toda a informação possível sobre as organizações responsáveis pela "revolução", compreendendo realmente a estrutura delas. O objetivo era descobrir quem eram os militantes e o organograma da organização. Mais ou menos como a polícia política brasileira fez. Em material mimeografado montado com todo o material recolhido de várias organizações da esquerda armada, em 1974 o DEOPS do Estado de São Paulo distribuiu para os outros estados um dossiê, contendo a estrutura geral das organizações, e todo o tipo de informação sobre cada uma delas: data de fundação, principais lideranças (nomes e codinomes), principais ações, princípios e

\footnotetext{
${ }^{5}$ FICO, Carlos. Como eles agiam: os subterrâneos da ditadura militar: espionagem e polícia política. Rio de Janeiro: Record, 2001.

${ }^{6}$ Ver Robin (M.-M.), Escadrons de la mort, l'École Française. Paris, La Découverte, 2004. O documentário realizado a partir deste livro pode ser visto on-line no site: http://www.mefeedia.com/entry/2926696
} 
ideologia. Para conseguir estas informações, o principal meio usado era o aprisionamento de militantes, e eventualmente de pessoas a eles relacionados, e seu interrogatório, utilizando a tortura para assegurar que a pessoa falasse.

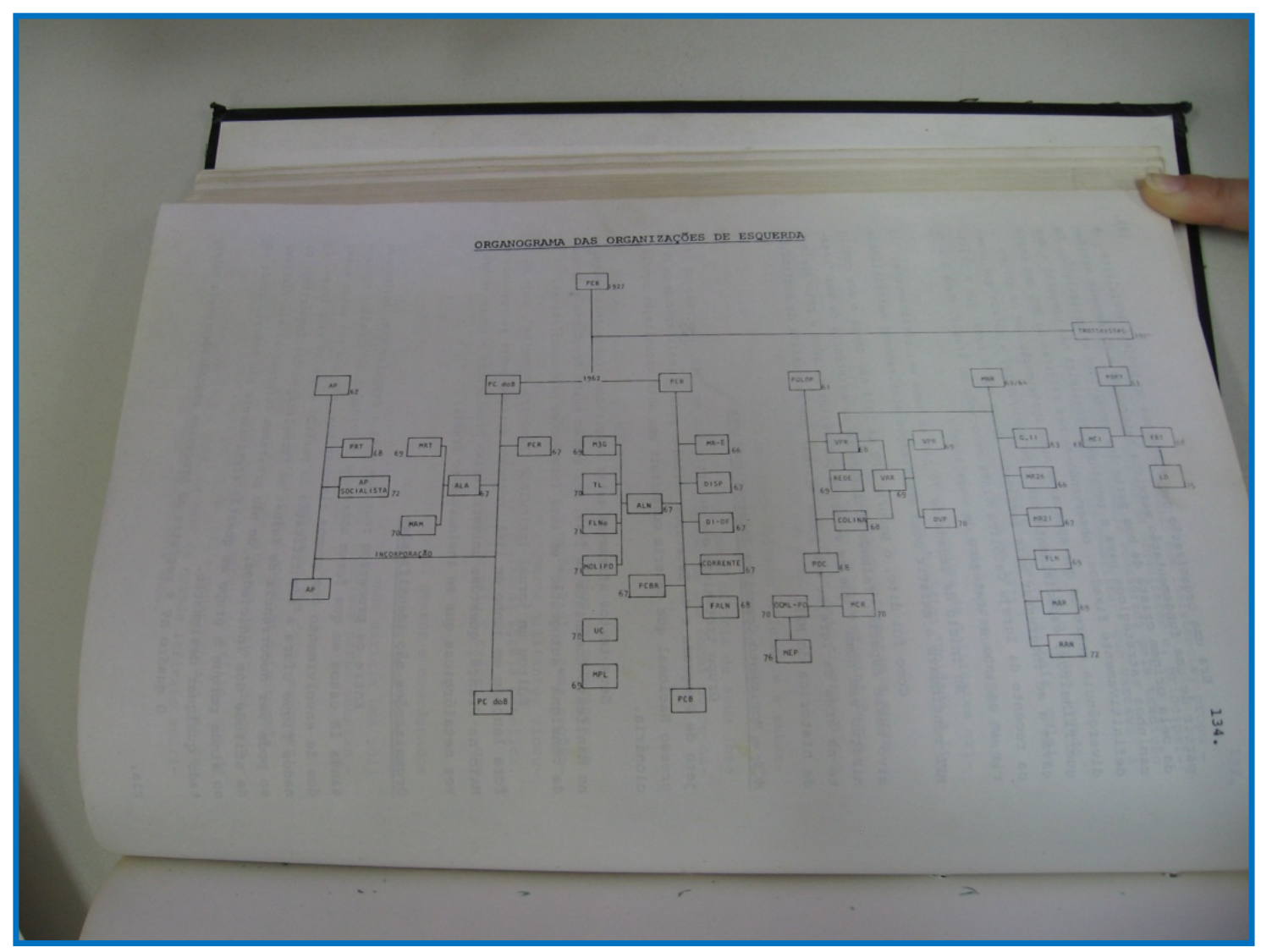

Documento constante dos anexos do Projeto Brasil Nunca Mais, Arquivo Edgard Leuenroth, Campinas, São Paulo. O mesmo documento pode ser encontrado no Arquivo Público do Estado de São Paulo, Acervo do DEOPS.

Este método, com variações, foi utilizado nos vários países do Cone Sul nos quais realizamos nossa pesquisa. E gerou arquivos muito sombrios, nem sempre acessíveis. No Brasil, apesar da polêmica atual pela abertura de todos os arquivos deste período, já que uma parte destes ainda não foi liberada para a consulta pública, o historiador Carlos Fico tem argumentado que a parte realmente oculta destes arquivos deve ser insignificante, tendo em consideração que muito já está disponível. A Coleção Brasil Nunca Mais, disponível para consulta no Arquivo Edgard Leuenroth, na Universidade de Campinas, SP, (http://segall.ifch.unicamp.br/site_ael/)é um exemplo disso. Segundo o próprio arquivo: 


\begin{abstract}
"O projeto Brasil Nunca Mais foi idealizado por Dom Paulo Evaristo Arns, então assessor do Cardeal Arcebispo de São Paulo e pelo Reverendo Jaime Wright, então pastor da Igreja Presbiteriana Unida. A coleção reúne cópias de mais de 700 processos dos presos políticos brasileiros do período da ditadura militar, de 1964-1985, reproduzidos dos Arquivos do Superior Tribunal Militar e Supremo Tribunal Federal. Contém informações sobre partidos e organizações visadas pela repressão bem como estudos sobre a tortura no Brasil e no mundo. A coleção apresenta seção Anexos, com 10.170 documentos reproduzidos, relativos a material encontrado em posse dos militantes políticos e anexados aos processos como "prova de subversão". A coleção abrange o período de 1964 a 1979 e pode ser reproduzida."

(http://segall.ifch.unicamp.br/site_ael/index.php?option=com_content\&vi ew $=$ article\&id $=107 \&$ Itemid $=90$, consulta em 28/03/2012)
\end{abstract}

Esta coleção foi formada de maneira sui generis: os processos e documentos que tramitavam na justiça eram disponíveis apenas para os advogados dos presos. Estes então pediam vistas nos processos, faziam fotocópias e devolviam os processos. A coleção está sendo digitalizada, pois como se constitui de fotocópias está rapidamente se apagando. Muitos arquivos estaduais também abriram a possibilidade de consulta a arquivos da época da ditadura, ligados à polícia política. Vários dos materiais são reproduções de correspondências e informações que eram repassadas de um estado a outro, ou mesmo de agências como o SNI, Serviço Nacional de Informação. Os documentos militares, entretanto tem acesso muito restrito e em muitos casos desconfiase que tenham sido destruídos, como no caso dos documentos sobre a Guerrilha do Araguaia, até hoje desconhecidos do público e dos pesquisadores.

Em outros países do Cone Sul, a questão é até mais complicada. Na Argentina por exemplo há a Comisión Provincial por la Memoria de La Plata, que abriga o acervo da DIPBA:

"El Archivo de la DIPBA (Dirección de Inteligencia de la Policía de la Provincia de Buenos Aires) es un extenso y pormenorizado registro de espionaje político - ideológico sobre hombres y mujeres a lo largo de medio siglo. La DIPBA fue creada en agosto de 1956 y funcionó hasta que, en el contexto de una reforma de la Policía de la Provincia de Buenos Aires en el año 1998, fue disuelta y cerrado su archivo." (http://www.comisionporlamemoria.org/archivo/?page_id=3 consulta em 28/03/2012) 
O acesso às informações, porém, é bem complicado e se dá através de fotocópias que devem ser pedidas a partir de uma seleção de documentos feita por funcionários do arquivo através de palavras chave, que não podem ser nomes de pessoas. Ou seja, o pesquisador indica palavras chaves e os arquivistas acessam os documentos, selecionam e fazem fotocópias, tarjando os nomes.

Por outro lado há acervos diferentes, iniciativas da sociedade civil como o CeDInCl - Centro de Documentación e Investigación de la Cultura de Izquierdas en la Argentina (http://www.cedinci.org/ ), fundado por um militante e sustentado por uma associação, atualmente associado a Universidad Nacional de San Martin, e o Memoria Abierta, Acción Coordinada de Organizaciones argentinas de Derechos Humanos (http://www.memoriaabierta.org.ar) que é um projeto de várias organizações de Direitos Humanos para o registro da memória da época da ditadura e das ações de resistência. $O$ CeDInCl guarda especialmente periódicos e outros documentos das organizações de esquerda. Já o Memória Abierta, tem uma política voltada à história oral.

No Chile também são organizações não governamentais que se encarregam de preservar a memória sobre a repressão e a resistência. Onde encontramos mais materiais neste país foi na FLACSO, que mantém uma biblioteca e um Fundo documental acessível on line, mediante assinatura, extremamente importante. E na Vicaria de la Solidaridad, organização ligada à Igreja Católica que prestava assistência social e legal às vítimas da repressão e suas famílias.

O acervo mais impressionante que encontramos em nossa pesquisa, foi o Centro de Documentación y Archivo para la Defensa de los Derechos Humanos, que fica no Museo de la Justicia em Assunção, Paraguai, também conhecido como Arquivo do Terror, que conserva os restos de um imenso fundo de arquivos compostos por relatórios de vigilância de muitos tipos de pessoas percebidas como oponentes do governo Paraguaio. A documentação deste arquivo mostra que as pessoas eram seguidas a cada passo e seus movimentos eram registrados e descritos. Entre estas pessoas se distinguem líderes estudantis, sindicalistas, padres e freiras católicos, todos os estrangeiros que chegavam ao país, as esposas e a família de "suspeitos de subversão", e muitos outros, incluindo 
Uma outra importantíssima fonte de dados para esse período são arquivos e coleções de documentos guardados em outros países. Nesta pesquisa tive a oportunidade de investigar aqui na França, na Biblioteca Internacional de Documentação Contemporânea, na Université de Paris X, Nanterre e no Arquivo Diplomático de Nantes. Na primeira há documentos os mais variados sobre a América Latina, sobre todo tipo de movimentos sociais, partidos políticos e organizações de esquerda, em vários dos países da América Latina. Documentos sobre o Circulo de Mulheres Brasileiras em Paris, por exemplo, que não existem no Brasil, podem ser encontrados lá, bem como sobre outros grupos de esquerda e do feminismo. No arquivo de Nantes, eu pesquisei apenas os relatórios e correspondências da Embaixada da França no Brasil, mas há um problema com datas, só se pode ver os arquivos até 30 anos antes. Como fiz essa pesquisa em 2004, só pude ver coisas até o ano de 1973.

Nos Estados Unidos há também muitos acervos. O mais prático e rico para nosso trabalho é a coleção de panfletos sobre a América Latina da University of Princeton, que está toda publicada em microfilmes, disponível em muitas bibliotecas e para a compra. São milhares de folhetos, panfletos e outras publicações, separados por países e temáticas, sendo que as temáticas Direitos Humanos e Mulheres e Gênero estão presentes. Outra importante coleção que tive a oportunidade de pesquisar, é claro, é o National Archives, cuja parte sobre América Latina está especialmente em College Park, Maryland. Neste caso são documentos produzidos no contato do Departamento de Estado dos Estados Unidos com as embaixadas e consulados nos vários países. Infelizmente muitos documentos foram retirados dos arquivos “classificados".

Temos então, para trabalhar com essa época das ditaduras no Cone Sul três tipos de documentação principais: a documentação dos arquivos policiais e judiciários, nem

\footnotetext{
7 Visitei este arquivo com Joana M. Pedro, Mirian A. Nascimento e Larissa M. Freitas em julho de 2010. http://www.pj.gov.py/contenido/132-informacion-general-museo2/334;

http://www.unesco.org/webworld/paraguay/historia.html
} 

procuram documentar a ação dos grupos de esquerda durante aquele período. Além disso, há os arquivos diplomáticos. As características da documentação, a forma de organização dos dados e o acesso são diferentes para cada uma. Mas é possível usar os dados de forma comparativa, na medida em que se faça o exercício crítico, sempre tão importante, com cada documento: de onde veio este documento, como foi produzido, por que e como foi guardado neste acervo.

No caso de nossa pesquisa há um desafio muito grande em usar estes arquivos, pois eles em nenhum momento foram pensados para uma investigação que prioriza o estudo do gênero no contexto das ditaduras. Tem sido muito interessante encontrar, porém, nos diversos arquivos, as marcas de como os discursos de gênero foram usados tanto na repressão, quanto na resistência.

Resistência é um conceito muito amplo. Normalmente pensado em oposição a “poder”, resistência pode ser qualquer tipo de ação individual ou coletiva realizada contra um governo, uma instituição, uma lei, uma ação repressiva. Para Foucault, toda relação de poder traz consigo uma ação de resistência. Se não há resistência, não há necessidade de uma ação de poder ou repressão. ${ }^{8}$ No contexto da Segunda Guerra Mundial, a resistência é uma questão muito estudada nos vários países ocupados pela Alemanha Nazista, especialmente a França. Mesmo em países como a Alemanha e a Itália, nos quais o Nazismo e o Fascismo dominaram os governos naquele período, a ideia de uma resistência é muito acalentada pela historiografia posterior. 9 Esta noção de resistência como um amplo leque de ações e movimentos contra uma ditadura, tirania, ou regime de exceção é usada por todo o mundo por historiadores, cientistas sociais e outros em contextos muito diversificados. ${ }^{10} \mathrm{E}$ é aplicado tanto para movimentos

\footnotetext{
${ }^{8}$ Ver: FOUCAULT, Michel. História da sexualidade.

9 PEUKERT, Detlev J. K. Inside Nazi Germany: conformity, opposition and racism in everyday life. New Haven: Yale University Press, 1987. SOO, Scott. Resisting in France and la vie inventée. Journal of Contemporary History, University of Sussex. 1 (2000), pp 1-10.

${ }^{10}$ RIDENTI, Marcelo. Resistência e mistificação da resistência armada contra a ditadura: armadilhas para
} 
armados como os Partisans na França, os movimentos de libertação da Algéria e em toda a África, como também para movimentos pacifistas como a luta de Nelson Mandela contra o Apartheid, na África do Sul, ou o movimento dos direitos humanos nos Estados Unidos.

Dessa forma penso que posso utilizar esta noção de resistência para incluir a guerrilha, movimentos de direitos humanos e mesmo organizações de familiares de presos e desaparecidos, assim como também outros tipos de movimentos, como associações profissionais e partidos de oposição no contexto das ditaduras do Cone Sul. Isto é importante pois, como já foi demonstrado por Marcelo Ridentti para o caso brasileiro, muitas vezes a resistência armada foi mistificada como sendo a única “verdadeira” resistência, como parece ser o caso do Chile também. Em outros contextos, percebemos que um movimento ou grupo é tomado frequentemente como o único representante da resistência, como no caso da Argentina, das Madres de la Plaza de Mayo. ${ }^{11}$

Por outro lado, a inclusão de toda esta ampla gama de grupos e movimentos, sob um mesmo "guarda chuva" tem seus próprios perigos, pois eles são muito diferentes, e às vezes até opostos em seus objetivos e estratégias. Para minha perspectiva investigativa, porém, uma diferença é crucial: o uso do gênero no discurso. As organizações armadas usaram frequentemente a masculinidade como um argumento para a luta contra a ditadura. Orgulho, honra, ação (versus passividade), força e capacidade de suportar todos os tipos de desafios físicos e morais em nome de um ideal, são usados para descrever como um guerrilheiro deveria ser, e explicar a ação. ${ }^{12}$ Por

pesquisadores. In: REIS, Daniel Aarão, RIDENTI, Marcelo e MOTTA, Rodrigo Patto Sá. (orgs.). O golpe e a ditadura militar: quarenta anos depois (1964-2004). Bauru, SP: Edusc, 2004., pp. 53-65, p. 54

${ }^{11}$ Não estou aqui defendendo que as "Madres" não sejam um movimento muito importante na resistência argentina, e mesmo no contexto sul-americano, apenas que elas não constituem toda a resistência.

${ }^{12}$ Para Che Guevara: "The guerrilla combatant is a night combatant; to say this is to say at the same time that he must have all the special qualities that such fighting requires. He must be cunning and able to march to the place of attack across plains or mountains without anybody noticing him, and then to fall upon the enemy, taking advantage of the factor of surprise which deserves to be emphasized again as important in this type of fight. After causing panic by this surprise, he should launch himself into the fight implacably without permitting a single weakness in his companions and taking advantage of every sign of weakness on the part of the enemy. Striking like a tornado, destroying all, giving no quarter unless the tactical circumstances call for it, judging those who must be judged, sowing panic among the enemy combatants, 
outro lado, o discurso de denúncia contra a violência da repressão utilizou o gênero de outra maneira, quase oposta. Um dos discursos mais usados por um grande número de denúncias na mídia era sobre o uso da tortura. Outro tipo de denúncia era sobre o desaparecimento de militantes, e destacava muitas vezes o desespero das mães e outros familiares com relação a este desaparecimento. Outro tipo ainda era a ênfase na injustiça de muitas prisões, já que muitas das pessoas presas não eram militantes políticos. Em todos estes discursos, o gênero é um importante elemento, como pretendo mostrar. Mas é importante ver como o conteúdo destas denúncias contradizem a noção de um guerrilheiro, homem ou mulher, feito nos moldes do "macho", que, citando Che Guevara, “...lança-se à luta implacavelmente, não permitindo uma única fraqueza em seus companheiros" ${ }^{13}$ e, conforme Carlos Marighela "é caracterizado por sua valentia e sua natureza decisiva." ${ }^{14}$ Porém quando apelam para os Direitos Humanos ${ }^{15}$ para denunciar as ditaduras, estas mesmas organizações humanizam os militantes, e, no mesmo movimento, mudam suas características de gênero.

\section{Mães dolorosas}

Analisando os materiais dessas organizações, percebe-se como as emoções e sentimentos ligados à maternidade foram mobilizados para sensibilizar a opinião pública. Parecia diferente dizer que um militante ou um guerrilheiro tinha sido torturado e estava desaparecido, do que uma mãe dizer: procuro meu filho.

\footnotetext{
he nevertheless treats defenseless prisoners benevolently and shows respect for the dead." GUEVARA, Ernesto Che. Guerrilla Warfare. P. 24.

${ }^{13}$ Ibidem, p. 24

14 MARIGHELA, Carlos. Minimanual do guerrilheiro urbano. 1969. (http://brasil.indymedia.org/media/2008/06//422822.pdf, consulted in 01/28/2011) Free translation.

${ }^{15}$ About Human Rights, see : HUNT, Lynn. A invenção dos Direitos Humanos: uma história. São Paulo: Cia das Letras, 2009.
} 


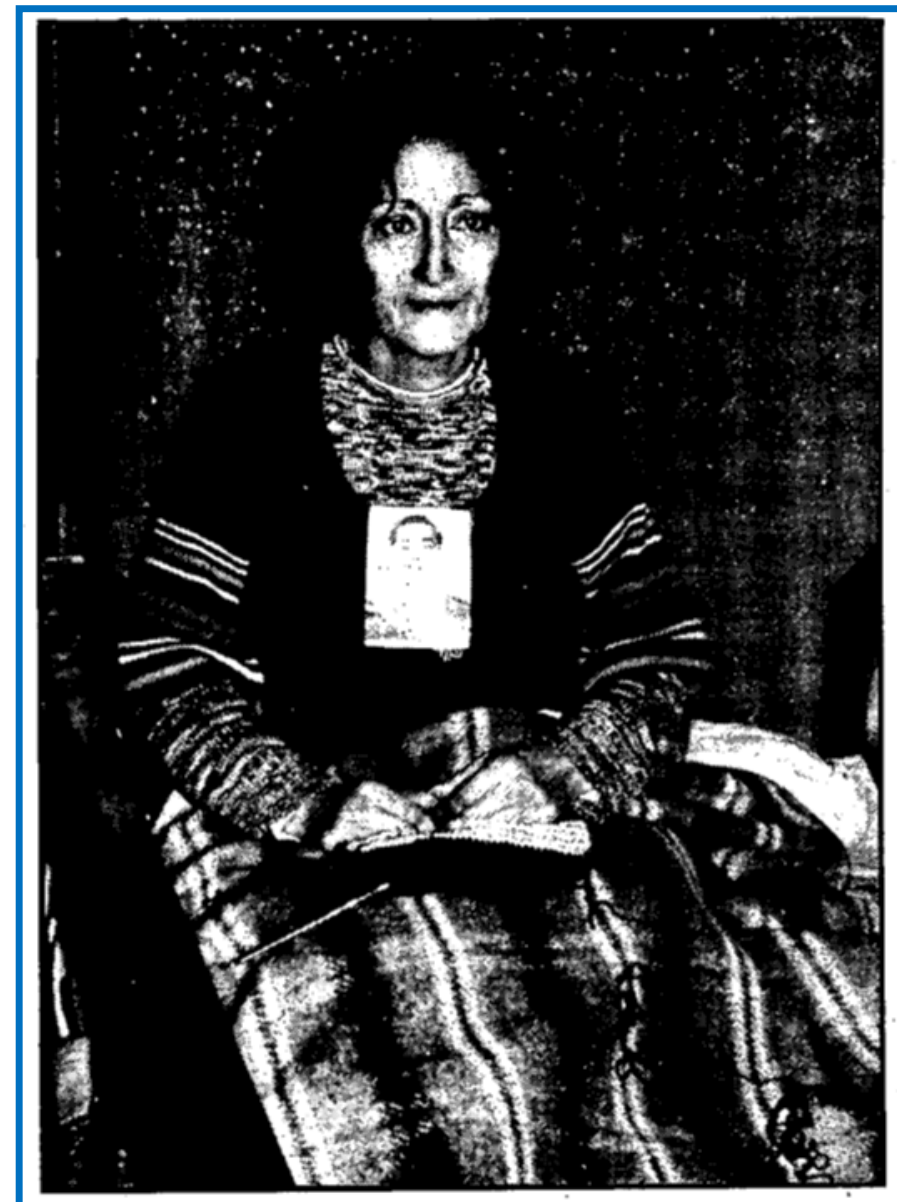

Todo esto me tiene muy enferma, pero no me impedirá seguir exigiendo justicia y el esclarecimiento de la suerte corrida por él en manos de sus aprehensores, en los cuales están los nombres de algunos de los encargados reos por el ministro Carlos Cerda.

\section{Orfilia Silva Corrales}

(Agrupación de Familiares de Detenidos Desaparecidos

Titulo: ¡Hasta encontrar la verdad! Detenidos - Desaparecidos, diciembre 1976, 1986 Colección: Fundación de Documentación y Archivo de la Vicaría de la Solidaridad, in: http://www.archivovicaria.cl/archivos/VS4b4f1f92850eb_14012010_1043am.pdf Consultado em 31/01/2011)

Esta imagem da mãe com o retrato do filho, é recorrente em todos os materiais, e mais do que nada simbolizou a denúncia das atrocidades cometidas nos vários países pelas ditaduras. 
As Madres de la Plaza de Mayo foram a organização que mais mobilizou esse discurso. Hoje dividida em duas organizações, a Madres de la Plaza de Mayo- Linea Fundadora e a outra por divergências e questões várias, o símbolo máximo dessa organização segue sendo a fralda branca na cabeça dessas senhoras que pedem o aparecimento de seus filhos com vida ou a punição dos responsáveis pelo seu assassinato.
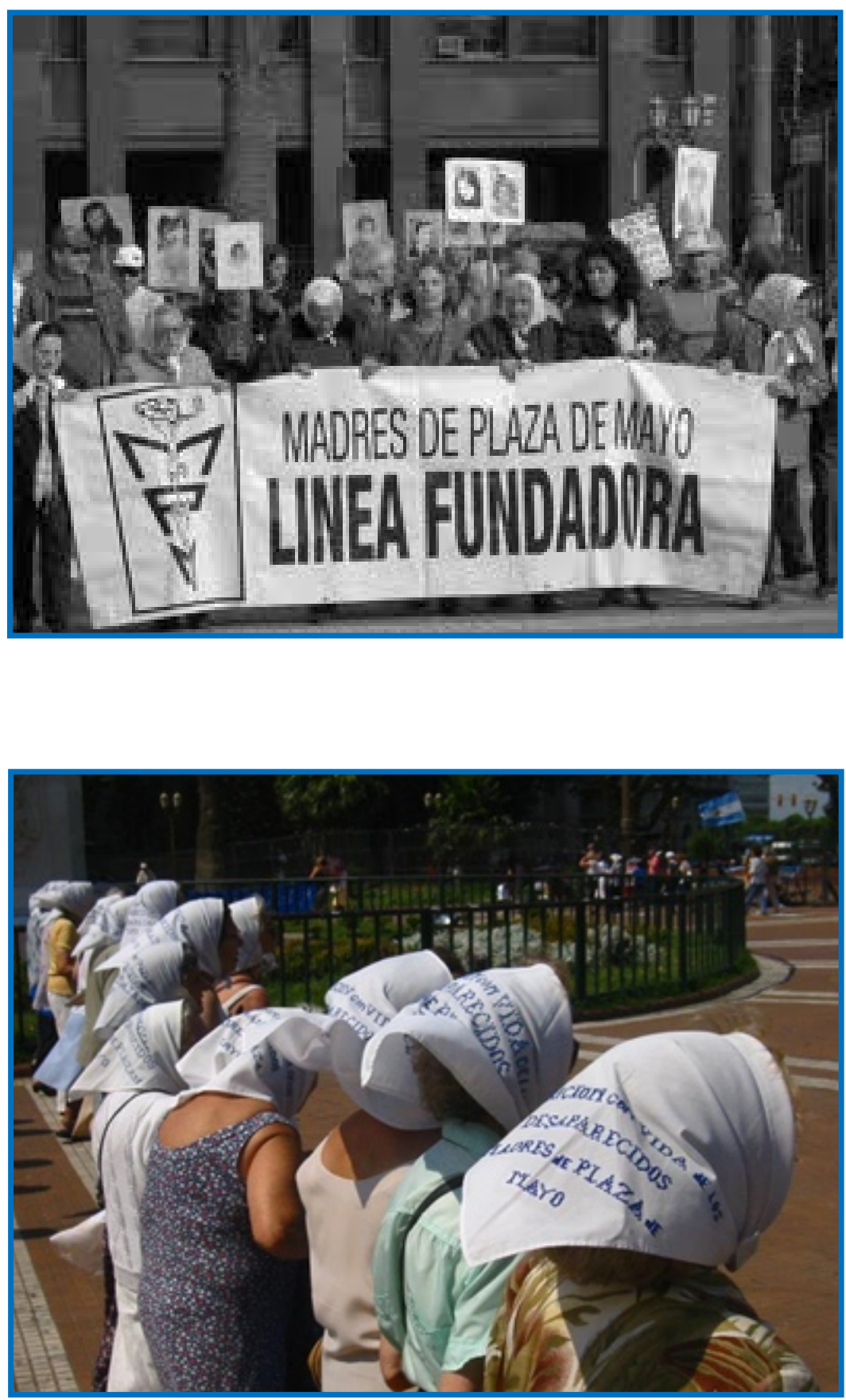


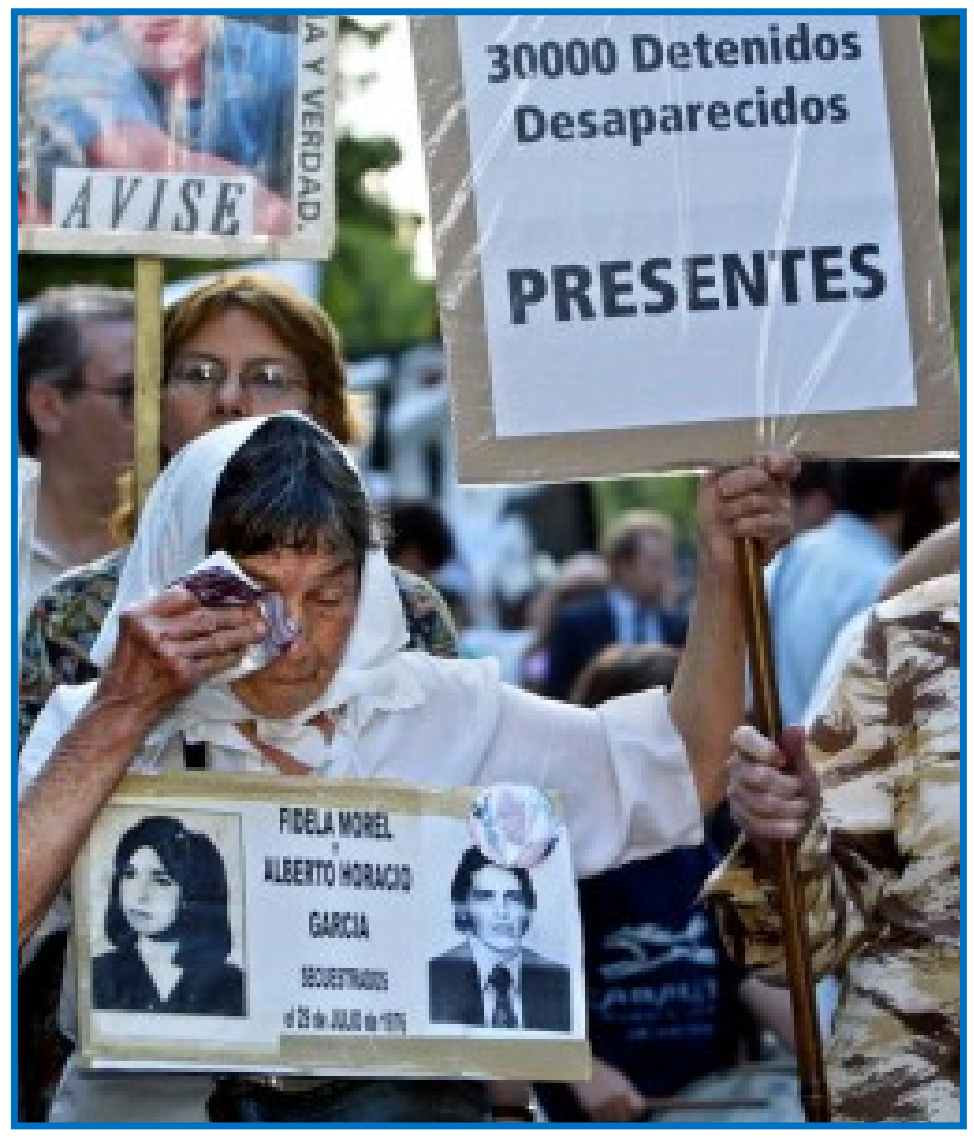

http://www.focoblanco.com.uy/2011/06/contra-las-madres-de-plaza-de-mayo/

A fralda remete ao cuidado das mães com seus filhos. Elas usam estrategicamente seu papel de mães, mães como aquelas que cuidam dos filhos, ligadas por um laço emocional muito forte a eles, para humanizar os guerrilheiros e militantes de esquerda. Acima de tudo, antes de serem guerrilheiros, ou terroristas como os governos militares os chamavam, esses jovens eram filhos e filhas, bebês que usaram fraldas, que receberam cuidados de suas mães, pessoas, humanos. O discurso delas é sempre neste tom emocional: 


\section{Las Madres de Plaza de Mayo seguiremos luchando, no solo con la palabra, sino poniendo el pecho y la ca- beza cada vez que sea necesario, por nuestros hijos, pero también por todos aquellos hombres y mujeres de esta tierra que sufren la injusticia de los opresores que siem- pre se esconden detrás de los uniformados de turno. $Y$ vamos a seguir luchando, porque nosotras estia- mos embarazadas para siempre de nuestros hijos, que es como decir de liberación y de esperanza.}

\section{4 de febrero de 1989}

Carta Abierta de la Asociacion Madres de Plaza de Mayo al Dr. Raul Alfonsin. 4/02/1988. Buenos Aires, Argentina. Human Rights in Argentina II - Panphlets. Princeton University Libraries,

Princeton, 1991. Microfilme. Consultado na Mckeldin Library, UMD College Park.

Elas dizem que estarão sempre grávidas de seus filhos, eles seguem sendo partes de suas vidas mesmo depois de mortos. Como diz Chico Buarque, em outra música dedicada ao tema da mãe que tem esse filho desaparecido, "a saudade é o revés de um parto, a saudade é arrumar o quarto, do filho que já morreu." ${ }^{16}$ Ludmila Catela explorou em sua tese a reconstrução dos familiares de desaparecidos após a perda de seus filhos, filhas, esposos, irmãos. A denúncia, a luta por informações, a necessidade de buscar apoios em outras famílias, na igreja, nas organizações de direitos humanos, faz com que toda a vida dessas pessoas se reorganize em torno destas pessoas que morreram, desapareceram, mas certamente não foram esquecidas. ${ }^{17}$ Processo semelhante foi analisado por Deusa Maria de Sousa sobre o grupo de familiares de desaparecidos do Araguaia ${ }^{18}$. Mas aqui estamos apenas chamando a atenção para como a emoção e o sentimento, expostos publicamente, tiveram importante papel na sensibilização da

\footnotetext{
${ }^{16}$ Chico Buarque de Hollanda, Pedaço de Mim, 1979. Opera do Malandro.

${ }^{17}$ CATELA, Ludmila da Silva. No Habrá Flores en la Tumba del Pasado. La Experiencia de Reconstrucción del Mundo de los Familiares de Desaparecidos. La Plata: Ediciones Al Margen, 2001.

18 SOUSA, Deusa Maria. Lágrimas e Lutas: a reconstrução do mundo dos familiares de desaparecidos políticos. Florianópolis, Universidade Federal de Santa Catarina, Tese de doutorado em História, 2011.
} 


\section{Tortura}

Lynn Hunt, no seu livro sobre a história dessa ideia de Direitos Humanos, mostra como a denúncia aos suplícios e torturas praticados no sistema penal na França e outros lugares do mundo, foi importante para a construção de uma opinião pública contrária ao uso destes meios e para a construção das declarações e leis que instituíram os Direitos Humanos na qualidade de direitos. Pois na América do Sul, nos países em que estamos falando, a denúncia à tortura praticada sistematicamente contra os militantes de organizações de esquerda e mesmo pessoas que por vezes nem faziam parte destas organizações, foi também extremamente importante.

James Green, no seu livro sobre a oposição à ditadura brasileira nos Estados Unidos, mostrou como as denúncias de tortura foram fundamentais para a criação de uma opinião pública naquele país contra a conjuntura política do que acontecia no Brasil. Isso se refletiu, após muitas denúncias, na política de Jimmy Carter a partir de 1977, de exigir dos governos da América do Sul o respeito aos Direitos Humanos. James Green fala, por exemplo, de uma peça de teatro encenada em 1974, que reconstituía, ao vivo no palco, cenas de tortura no Brasil e que teve grande repercussão: ${ }^{19}$

\footnotetext{
${ }^{19}$ GREEN, James N. Apesar de vocês. Oposição à ditadura brasileira nos Estados Unidos, 1964-1985. São Paulo: Companhia das Letras, 2009.
} 


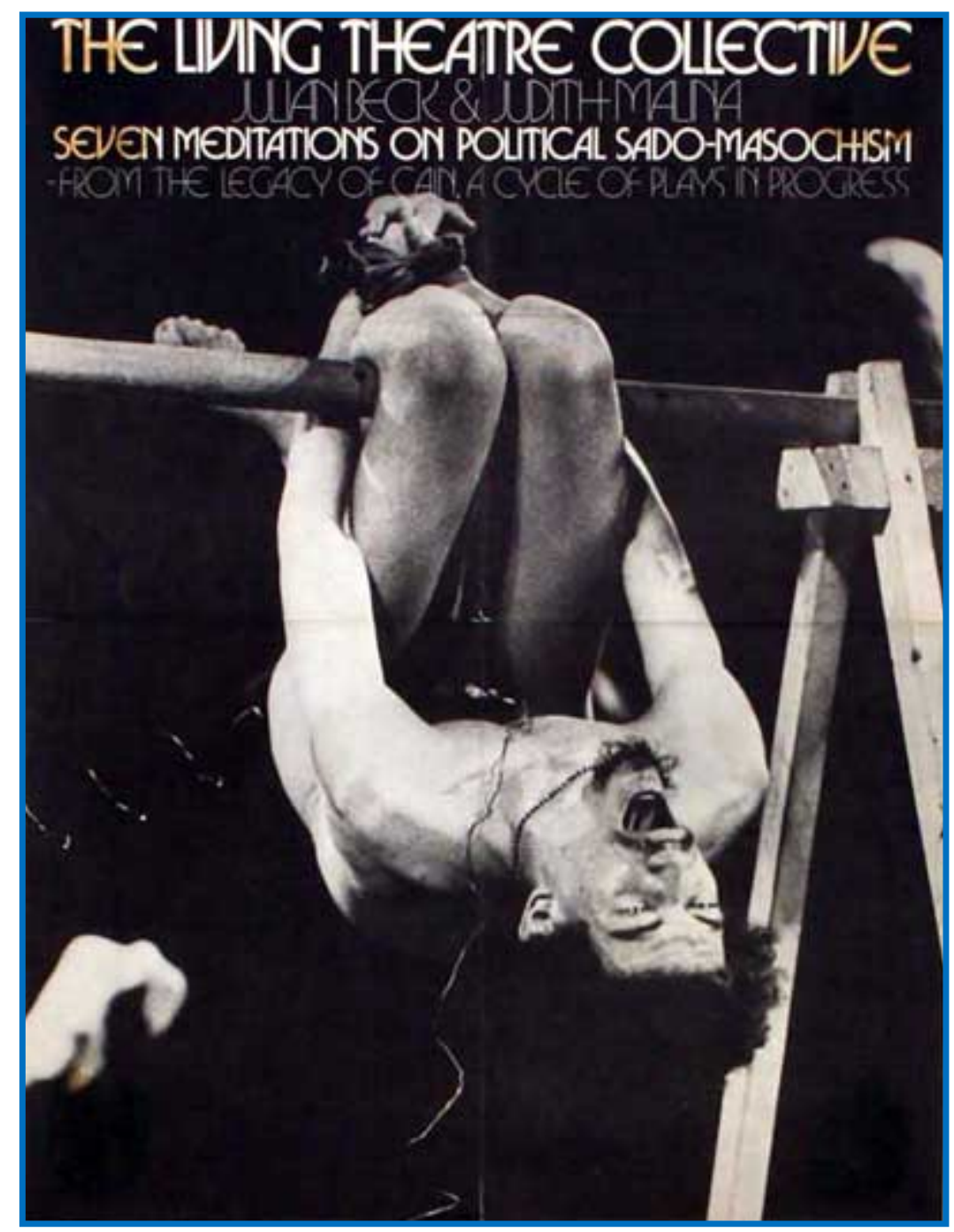

http://www.thelodownny.com/leslog/2011/03/living-theatre-revisits-seven-meditations-onpolitical-sado-masochism.html/smopsm

A tortura, como eu já coloquei acima, humaniza também o militante, quando a pessoa começa a descrever o que se passava naquelas câmaras. E o gênero foi também muito usado nas denúncias. De certa forma, parece que quando se fala de tortura com mulheres, crianças, e especialmente, mulheres grávidas, parece que a denúncia ganha em peso, torna-se mais séria, atinge mais a emoção. 


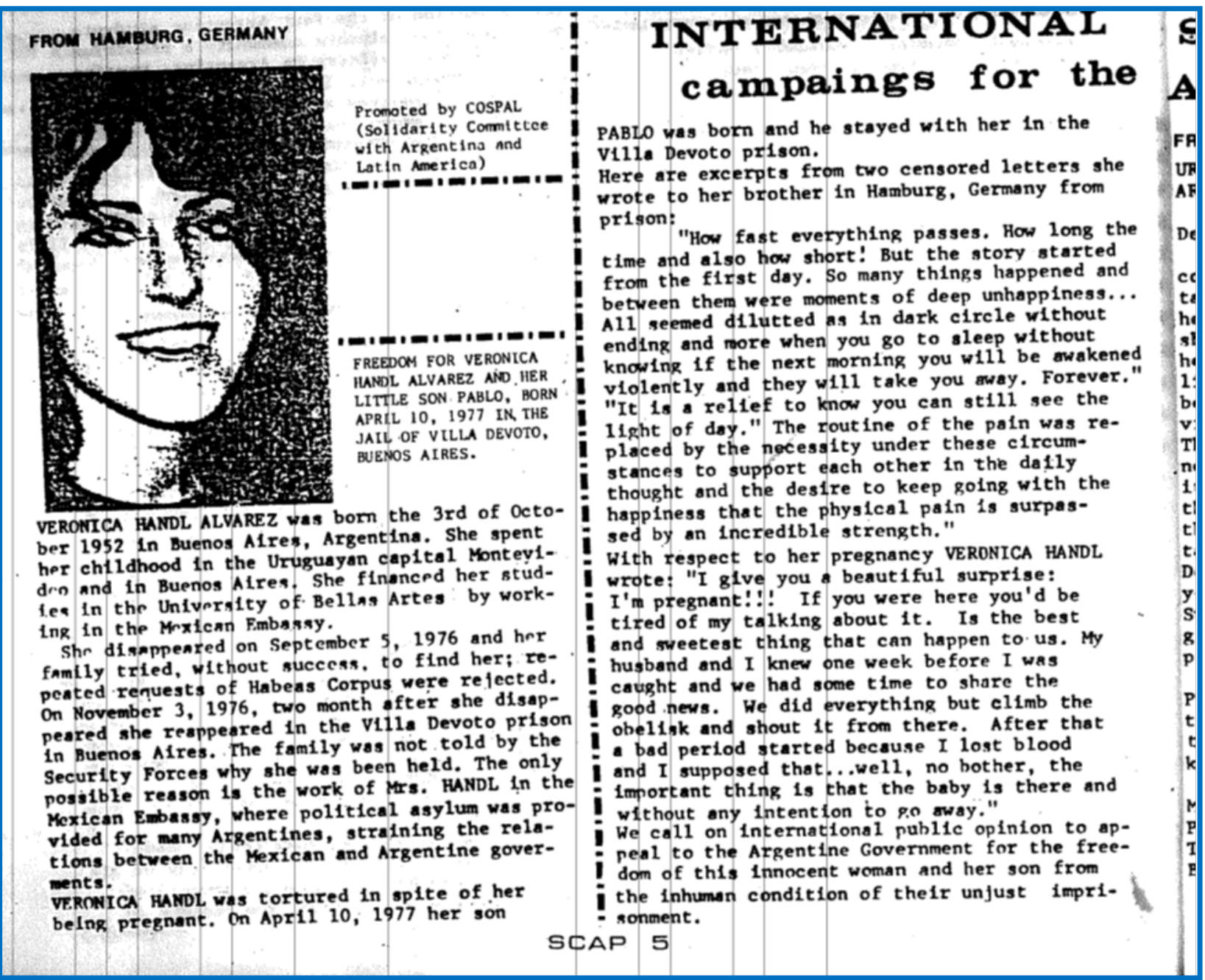

A denúncia acima se refere a uma mulher, Veronica Handl, torturada mesmo estando grávida, e exige sua libertação e de seu filho, Pablo, que teria nascido na prisão, em 1977, na Argentina. Todo

o discurso remete a um tom emocionado, que apela para a injustiça da prisão e as condições

desumanas de seu aprisionamento: "Chamamos a opinião pública internacional a apelar ao Governo Argentino pela liberdade desta mulher inocente e seu filho das condições desumanas de seu injusto aprisionamento." (tradução livre)

Da mesma forma foram denunciados casos como esses em vários lugares. A história de Maria Amélia Almeida Telles e sua irmã Criméia, por exemplo são histórias que tem sido denunciadas repetidamente e que geram sempre um sentimento de injustiça e muita indignação. Maria Amélia era militante do Partido Comunista do Brasil (PCdoB) e trabalhava especialmente na escrita, composição e impressão do jornal do partido, em São Paulo, quando foi presa em 1972. Criméia era enfermeira e durante algum tempo atuou no Araguaia, com o grupo depois chamado de Guerrilha do Araguaia. Como engravidou, veio para São Paulo, estabelecer contatos para o grupo. A prisão de Maria 
Maria Amélia foi muito torturada e por algum tempo sustentou a versão de que sua irmã seria uma doméstica, tentando ganhar tempo. Como Criméia estava grávida de 8 meses e César era tuberculoso e diabético, muitas vezes Amelinha era torturada na frente deles, para que eles falassem. Os filhos ficaram durante algum tempo, uma ou duas semanas, na mesma prisão, sob a guarda de policiais, e eram levados para ver a mãe algumas vezes, servindo como uma tensão adicional para esta, pois os policiais faziam ameaças. Ela conta que uma vez, estando ela na cadeira do dragão, os filhos foram trazidos à sala de torturas, e o filho perguntou: mamãe, porque o papai está verde e você está azul? Ela então se deu conta que estava toda coberta de hematomas, toda roxa. ${ }^{20}$ Amelinha deu esses depoimentos ao Brasil Nunca Mais, a jornais e a auditórios cheios. E, em uma ação inédita, junto de sua família, conseguiu judicialmente responsabilizar o Coronel Brilhante Ustra por ter ordenado a tortura.

Se estes arquivos abrigam memórias duras, tristes, difíceis, eles abrigam igualmente uma história de pessoas, de mulheres e homens, que nunca desistiram, que resistiram, que utilizaram as armas da emoção e dos sentimentos, do gênero, da denúncia, para construir um outro tempo. Eles abrigam uma esperança.

\footnotetext{
${ }^{20}$ TELLES, Maria Amélia Almeida. In: Gênero, Feminismos e Ditaduras no Cone Sul. PEDRO, Joana Maria WOLFF, Cristina Scheibe. Florianópolis: Mulheres, 2010, p. 264
} 
